\title{
INFLAMATUAR BARSAK HASTALIĞINDA OSTEOPOROZ VE VERTEBRA KIRIKLARI
}

\author{
Osteoporosis and Vertebral Fractures in Inflamatory Bowel \\ Disease
}

Zeynep Tuğba Özdemir' ${ }^{1}$ Arif Acar², Laika Karabulut ${ }^{2}$

\section{ÖZET}

'Bozok Üniversitesi Tıp Fakültesi Araştrrma ve Uygulama Hastanesi Iç Hastalıkları Anabilim Dalı Yozgat

'S.B. Okmeydanı Eğitim Araştırma Hastanesi lç Hastalıkları Kliniği istanbul

Zeynep Tuğba Özdemir, Yrd.Doç.Dr. Arif Acar, Uzm. Dr.

Laika Karabulut, Doç. Dr.

\section{lletişim:}

Yrd.Doç.Dr. Zeynep Tuğba Özdemir Bozok Üniversitesi Tip Fakültesi Araştrrma ve Uygulama Hastanesi İç Hastalıkları Anabilim Dalı Yozgat Tel: 03542177050 e-mail: drtugba09@gmail.com

Geliş tarihi/Received:17.06.2013 Kabul tarihi/Accepted:25.10.2013

Bozok Tip Derg 2014,4(1):48-54 Bozok Med J 2014:4(1):48-54
Amaç: Dünyada en sık görülen metabolik kemik hastalığı olan osteoporoz (OP) İnflamatuar Barsak Hastalığı (IBH) olan hastalarda yüksek oranda (\%32 -77) görülmektedir. İBH' nda düşük Kemik mineral yoğunluğu (KMY) etyolojisinin multifaktöriyel olduğu düşünülmektedir.

Bu çalışmada IBH olanlarda osteoporoz nedenlerini saptayarak; ülseratif kolit (ÜK) ve Crohn hastalarını KMY açısından karşılaştırmak; her iki grupta vertebral kırık sıklığını ve kırık varlığında şiddetini saptamak hedeflenmiştir.

Gereç ve Yöntemler: Çalışmamıza 2009 yılında Okmeydanı Eğitim ve Araştırma Hastanesi Gastroenteroloji Kliniğinden takipli 18 ÜK ve $33 \mathrm{CH}$ dahil edildi. Dual enerjili $\mathrm{x}$-ray absorpsiyometrisi (DEXA) ile KMY ölçümü ve Genant yöntemi ile de vertebral kırıklar tespit edildi.

Bulgular: Yaş ortalamaları 43 olan her iki grupta VKi,hastalık yaşı, tutulum yeri,steroid-kalsiyum/D vitamini alımı ile KMY arası ilişki saptanmadı. ÜK grubunda lomber vertebralarda \%20-femur boynunda \%4 osteoporoz; $\mathrm{CH}$ grubunda \%13-\%7 oranında osteoporoz saptandı. ÜK hastalarının $\% 68$ 'inde, Crohn hastalarının \%48'inde kırık tespit edildi. Her iki grupta kırık oluşumunda yaş ve cinsiyet açısından fark görülmedi. KMY ile kırık oluşumu arasında da ilişki mevcut değildi.

Sonuç: IBBH'nda osteoporoz (OP) patogenezi multifaktöriyeldir ve erken yaşta OP oluştuğu için önemli bir morbidite nedenidir.

Anahtar Kelimeler: Inflamatuar Barsak Hastalıkları; Osteoporoz; Crohn Hastalığı

\section{SUMMARY}

Objective: Osteoporosis(OP) is the most common metabolic disease and seen higher in inflamatory bowel disease (IBD) (\%32-77). The etyology is thought as multifactorial. In this study we looked at the causes of $\mathrm{OP}$ in $\mathrm{IBD}$. We compared bone mineral density (BMD) in ülserative colitis (UC) and crohn group (CD) and determined the severity of vertebral fracture frequency.

Mateials and Methods: $18 \mathrm{UC}$ and $33 \mathrm{CD}$ patients followed in Okmeydanı Eğitim and Araştırma Hastanesi Gastroenterology Clinical in 2009. BMD measured by Dual-energy X-ray absorptiometry (DXA, DEXA) and vertebral fractures are fined with Genant method.

Results: Mean age was 43. No relation found between BMI, involvement in disease, disease age, using corticosteroid-calcium-D vitamins and BMD in both group. The patients in UC has \%20 osteoporosis in lumbal spines and \%4 in femoral neck; patients in CD has \%13-\%7 osteoporosis. There was $\% 68$ spine fracture in UC, $\% 48$ in CD. There were no differences between fracture and age - sex. No relation found between fracture formation and BMD.

Conclusion: The pathogenesis of osteoporosis (OP) in $\mathrm{IBH}$ is multifactorial and an important cause of morbidity.

Key Words: Inflamatory Bowel Diseases; Osteoporosis; Crohn's Disease 


\section{Giriş}

Osteoporoz kemik kütlesinde azalma ve kemik yapısında bozulma ile karakterize progresif bir metabolik kemik hastalığıdır. Dünyada en sık görülen metabolik kemik hastalığı olmakla birlikte klinikte yol açtğı kırıklar sonucu önemli bir morbidite ve iş kaybı nedenidir. Dünya genelinde yaklaşık iki yüz milyon nüfusu etkilemektedir. Osteoporoz tanısında kemik yoğunluğu ölçümünde DEXA tekniği altın standart olarak kabul edilmektedir: $T$ skoru>-1 normal ;-1>T skoru>-2,5 osteopenik; T skoru<2,5 osteoporotik olarak değerlendirilmektedir.

Inflamatuar barsak hastalığında osteoporoz prevelansı \%15 düzeyinde bildirilmektedir $(1,2)$. İnflamatuar Barsak Hastalığı (IBH) ile ilişkili osteoporozda inflamatuar sitokinlerin salınımı, persistan hastalık aktivitesi,malabso rbsiyon,malnütrisyon,kortikosteroid kullanımı,fiziksel aktivite azlığı,sigara kullanımı,seks hormonlarının düzeyi, vitamin D eksikliği gibi birçok neden suçlanmaktadır; düşük mineral yoğunluğunun patogenezinin multifaktöriyel olduğu ileri sürülmektedir (3). Artan osteoporoz prevelansına bağlı olarak hem ülseratif kolit (ÜK) hem de Crohn hastalığı $(\mathrm{CH})$ grubunda vertebral deformite sıklığı da artmaktadır. Osteoporoz uzun bir sublinik döneme sahip olduğu ve hastalarda kırık oluşana kadar klinik sessiz seyrettiği için genelde tanıda geç kalınmaktadır; bu durum ise artmış morbidite ve mortaliteye neden olmaktadır. İnflamatuar barsak hastalarında kırık riskini belirlemek adına birçok çalışma yapılmış; \%40 lara varan oranlarda kırık riski saptanmıştır $(4,5)$.

\section{GEREÇ VE YÖNTEMLER}

Bu çalışmaya SSK Okmeydanı Eğitim ve araştırma Hastanesi Gastroenterohepatoloji polikliniğinde 2009 yılında takip edilen 18-69 yaş arası $33 \mathrm{CH}$ ve 18 ÜK hastası dahil edildi. Tüm hastalara ÜK ve $\mathrm{CH}$ tanıları histolojik, endoskopik, radyolojik ve klinik kriterlere dayanılarak konulmuştu. Son 6 ay içinde kontrol amaçlı olarak istenmiş olan lomber vertebra ve femur boynu kemik yoğunluğu ölçümleri ve 2 yönlü (AP+lateral) torakolomber vertebra grafileri değerlendirildi. Dual enerjili $x$-ray $a b-$ sorpsiyometrisi (DEXA) ile ölçülen $T$ skor değerlerine göre -1 'in üstü normal, -1 ve -2.5 arası osteopeni, -2.5'den küçük değerler osteoporoz olarak kabul edildi.

Tüm hastalar; cinsiyet, sigara kullanımı, Vücut Kitle Indeksi (VKi), kadınlarda kontrasepsiyonel durum,apendektomi öyküsü, hastalık yaşı ve tutulum yeri, barsak rezeksiyonu anamnezi, steroid-kalsiyum/D vitamini kullanımı, ekstraintestinal belirti ve komplikasyon açısından değerlendirildi. Bu parametrelerle $\mathrm{KMY}$ arasındaki ilişki araştırıldı. ÜK ve $\mathrm{CH}$ hastalarının KMY ölçümleri karşılaştıııldı. Aynı zamanda hastaların 2 yönlü torakolomber vertebra grafilerine bakılarak kırık saptanan olgularda Genant yöntemi ile kırık derecesi ve kırık tipi belirlendi. KMY kırık ilişkisi araştrıldı. Semikantitatif omurga kırığı değerlendirme yöntemlerinden biri olan Genant yönteminde değerlendirme şu şekilde yapılmaktadır; Lateral spinal radyografilerde T4-L4 arası vertebralar, ön, orta ve/veya arka yüksekliklerindeki azalma oranı ve vertebra cisimlerinde meydana gelen azalmaya göre derecelendirilir (6). Buna göre; Grade 0: Normal, Grade I: Hafif deformasyon. Ön, orta ve/veya arka yüksekliklerde yaklaşık \%20-25 azalma ve vertebra cisminde \%10-20 azalma, Grade II:Orta derecede deformasyon. Ön, orta ve/veya yüksekliklerden herhangi birinde yaklaşık \%25-40 azalma ve vertebra cisminde \%20-40 azalma, Grade III:Şiddetli deformasyon.Ön,orta ve/veya arka yüksekliklerden herhangi birinde ve vertebra cisminde yaklaşık \%40 azalma olmasıdır (7).

Çalışma dışı bırakılma kriterleri:(osteoporoza neden olabilecek ikincil bir hastalığı ya da ilaç kullanımı olan hastalar) Hipertiroidizm, hiperparatiroidizm, Cushing hastalığı, Diabetes mellitus, Romatoid artrit, multiple myelom,lenfoma,lösemi,subtotal gastrektomi operasyonu, Kronik Obstrüktif Akciğer Hastalığı (KOAH) tanılı kişiler ve de;Son 6 ay içerisinde tiazid diüretiği, antikonvülzan, heparin, metotreksat, antipsikotik, antidepresan, antiparkinson, HRT kullanımı olanlar araştırmaya alınmadı. 
ÖZDEMIR ve ark.

Inflamatuar Barsak Hastalığında Osteoporoz Vertebra Kırıkları
Bozok Tıp Derg 2014,4(1):48-54

Bozok Med J 2014;4(1):48-54

\section{İstatistiksel Değerlendirme}

Tüm istatiksel analizler "SPSS for Windows" (SP-SPSS versiyon 13) kullanılarakanalizedildi. Sonuçlarortalama \pm SD (standart sapma) ve ortalama \pm SEM(standart eror mean) olarak verildi. KMY ölçümleri ortalama \pm SD olarak verildi. İki bağımsız grubun ortalamaları arasında fark olup olmadığını saptamak için student $t$ testi yapıldı. İkiden çok grubun ortalamalarını karşılaştırmak için varyans analizi (ANOVA) kullanıldı. Gruplar arasında oranları karşılaştırmak için, non parametrik yöntem olan ki-kare testi yapıldı. İki değişken arasında bağınt olup olamadığını saptamak için korelasyon araştırmaları (pearson korelasyon testi) ile yapıldı. KMY ölçümü için olası değişkenler olan hastalık yaşı, cinsiyet, VKi, hastalık süresi, kümülatif steroid dozu, operasyon durumu için regresyon analizi yapıldı ve $p<0.05$ değeri istatiksel olarak anlamlı kabul edildi.

\section{BULGULAR}

Çalışmaya 18 ülseratif kolit (8 kadın \%44,10 erkek \%46),33 crohn hastası (21 kadın \%64, 12 erkek \%36) olmak üzere toplam 51 hasta dahil edildi. Hastaların ortalama yaşı $43.5 \pm 11.23$, ortalama hastalık süresi ise $97,6 \pm 62$ ay (ortalama 8 yıl) idi. Hasta grubunun \%57 si kadınlardan, \%43 ü de erkeklerden oluşmakta idi. Ortalama vücut kitle indeksi $25,8 \pm 4,7 \mathrm{~kg} / \mathrm{m} 2$ idi. Yapılan çalışmalarda düşük VKi nin düşük KMY için bağımsız bir risk faktörü olduğu belirtilse de çalışmamızda sadece 2 hastamız normalin alt sınırında VKI’ne sahipti ve VKI ile KMY arasında ilişki saptanamadı.

Hastaların demografik özelliklerine bakıldığında ise Crohn hastalarında anlamlı düzeyde daha fazla sigara içimi(\%51), kalsiyum-D vitamini kullanımı (\%45), hastalık süresince barsak rezeksiyonu geçirmiş olma (\%33) ve apendektomi öyküsü(\%40) mevcut idi. Yapılan çalışmalarda sigara kullanımının kadın IBH hastalarda düşük KMY ile beraber olduğu ve bu ilişkinin VKi, ilaç tedavisi ve hastalık tipi ile herhangibir ilişkisi olmadığı belirtilmiştir. Hasta grubumuzda sigara içen kadınların \%40 ında lomber bölgede ; \%50'sinde femur boynunda; erkeklerin \%50 sinde lomber bölgede ,\%25 inde femur boynunda osteopeni saptandı. IBH'nda hem diyetle alım yetersizliği hem de emilim bozukluğuna bağ| olarak özellikle Crohn hastalarında D vitamini eksikliği görülmektedir ve OP gelişimini hızlandırmaktadır. Fakat çalışmamızda kalsiyum/D vitamini kullanımı ile KMY arasında ilişki gözlenmedi. Steroid tedavisi özellikle kümülatif steroid dozu OP gelişiminde önemli katkıya sahiptir. Birçok çalışmada steroid alımına bağlı KMY unda belirgin azalma ve kırık riskinde artış saptanmıştır. Hasta grubumuzda her iki grupta steroid kullanım açısından farklılık bulunmadı. Bu değer bir anlamda steroid tedavisi başlanan hastalarımıza erken dönemde aynı zamanda kalsiyum ve D vitamini replasmanı yapılmasına bağlandı.

Hastalar normal, osteopenik ve osteoporotik olarak sınıfladırıldığında L1, L2, L3, L4, L1-4 ve femur boynu bölgelerindeki kemik yoğunluğu ölçümlerine göre ÜK ve $\mathrm{CH}$ grubu arasında normal, osteopenik ve osteoporotik olguların dağılmı açısından istatistiksel olarak anlamlı farklılık saptandı. ÜK grubunda L1-L4 düzeyinde \%24osteopeni,\%10 osteoporoz; $\mathrm{CH}$ grubunda \%36 osteopeni,\%13 osteoporoz mevcut idi. ÜK grubunda femur boynu düzeyinde \%24 osteopeni,\%4 osteoporoz; $\mathrm{CH}$ grubunda \%36 osteopeni,\%7 osteoporoz mevcut id (Tablo 1).

ÜK hastalarının \%57 sinde pankolit görülürken Crohn hastalarının \%54 ünde ince ve kalın barsağın birlikte tutulumu mevcut idi; fakat her iki grup arasında tutulum yeri ve T skorları açısından anlamlı ilişki bulunamamıştır. Her iki grup hastalıkta hastalık yaşı ile lomber vertebra ve femur boynu T skorları arasında istatistiksel olarak anlamlı ilişki bulunamadı. 
Tablo 1: Her iki grubun KMY değerlerine (normal-osteopenik-osteoporotik) göre kıyaslanması

\begin{tabular}{|c|c|c|c|c|}
\hline & & $\begin{array}{l}\text { Ülseratif Kolit } \\
(\mathrm{n}=18)\end{array}$ & $\begin{array}{l}\text { Crohn hastalığı } \\
(\mathrm{n}=33)\end{array}$ & \\
\hline & Normal & $8(\% 44)$ & $14(\% 42)$ & \\
\hline \multirow[t]{3}{*}{ L1 - T } & Osteopeni & $8(\% 44)$ & $15(\% 45)$ & $\chi^{2}: 25.42$ \\
\hline & Osteoporoz & $2(\% 12)$ & $4(\% 13)$ & P:0.003 \\
\hline & Normal & $8(\% 44)$ & $15(\% 45)$ & \\
\hline \multirow[t]{3}{*}{ L2-T } & Osteopeni & $7(\% 38)$ & $14(\% 42)$ & $\chi^{2}: 15.87$ \\
\hline & Osteoporoz & $3(\% 18)$ & $4(\% 13)$ & $\mathrm{P}: 0.02$ \\
\hline & Normal & $12(\% 66)$ & $16(\% 48)$ & \\
\hline \multirow[t]{3}{*}{ L3-T } & Osteopeni & $5(\% 27)$ & $13(\% 39)$ & $\chi^{2}: 27.01$ \\
\hline & Osteoporoz & $1(\% 7)$ & $4(\% 13)$ & P:0.03 \\
\hline & Normal & $14(\% 75)$ & $14(\% 42)$ & \\
\hline \multirow[t]{3}{*}{ L4-T } & Osteopeni & $3(\% 18)$ & $14(\% 42)$ & $\chi^{2}: 30.42$ \\
\hline & Osteoporoz & $1(\% 7)$ & $5(\% 16)$ & P:0.01 \\
\hline & Normal & $12(\% 66)$ & $17(\% 51)$ & \\
\hline \multirow[t]{3}{*}{ L1-L4 T } & Osteopeni & $4(\% 24)$ & $12(\% 36)$ & $\chi^{2}: 16.94$ \\
\hline & Osteoporoz & $2(\% 10)$ & $4(\% 13)$ & P:0.04 \\
\hline & Normal & $13(\% 72)$ & $19(\% 57)$ & \\
\hline Femur & Osteopeni & $4(\% 24)$ & $12(\% 36)$ & $\chi^{2}: 22.02$ \\
\hline Boynu T & Osteoporoz & $1(\% 4)$ & $2(\% 7)$ & $P: 0.03$ \\
\hline
\end{tabular}

\section{KMY: Kemik mineral yoğunluğu}

$\mathrm{CH}$ grubunda daha fazla sayıda komplikasyon geliştiği görüldü. Komplikasyon dağılımında ise en fazla striktürel $\mathrm{CH}(\% 36)$ olgusu mevcut idi. Fakat her iki hastalık birlikte değerlendirildiğinde komplikasyon gelişimi açısından anlamlı düzeyde ilişki bulunamadı. Her iki hastalık grubunda da en sık extraintestinal bulgu olarak artraljiye rastlandı (ÜK grubunda \%28, CH grubunda \%54). Extraintestinal bulgu dağılımı açısından değerlendirildiğinde iki grup arasında anlamlı farklılık görülmedi. Kadınlarda gebelik sayısı ile L1-4 bölgesi kemik yoğunluğu düzeyi (t skoru) arasında anlamlı ilişki bulunamadı.

Direkt grafilerde torakal ve lomber bölgedeki ön-orta ve arka kolondaki vertebra yükseklikleri değerlendirildi. Herhangi bir kolonda \%20’nin üzeri yükseklik kaybı kompresyon kırığı olarak değerlendirildi. Buna göre ÜK hastalarının \%68'inde, Crohn hastalarının \%48'inde kırık tespit edildi. Toplamda \%52 oranında kırık mevcut idi.

Her iki hastalık grubunda kompresyon kırığı oluşumu ile yaş ve cinsiyet arasında istatistiksel olarak anlamlı dü- zeyde ilişki bulunamadı. Vertebral kolonun ön kısmında kırık(arka kolona kıyasla) görüldüğünde kama tipi;orta kolondaki kırık plaka tipi ve tüm kolonlardaki yükseklik kaybı da ezilme tipi kırık olarak adlandırıldı. Çalışma grubumuzda hem kadınlarda hem de erkeklerde daha yüksek oranda kama tipi kırık mevcut idi. Her iki grup hastalıkta; en fazla kırık KMY'u (L1-4 ve femur boynu T skorlarına bakıldığında ) normal olan hastalarda tespit edildi.ÜK ve $\mathrm{CH}$ grubunda L1-4 ve femur boynu KMY değerlerinin kırık oluşumu ile istatistiksel olarak anlamlı düzeyde ilişkisi saptanamadı.

Her iki hastalık grubunda kırı̆̆ tespit edilenlerin \%9.8 inde 1.derece, \%39,2 sinde 2.derece, \%3.9 unda 3. derece kırık bulundu. Hastaların \%31 inde kama (wedge) tipi, \%9.8 inde plaka (endplate) tipi, \%11,8 inde ise ezilme (crush)tipi kırık mevcut idi.Kırıkların lokalizasyonu değ erlendirildiğinde ise \%2sinin üst torakal bölge (T1-T2-T3-T4), \%31,4 ünün orta torakal bölge (T5-T6T7-T8), \%17,6 sının da alt torakal bölgede (T9-T10-T11T12) olduğu belirlendi. 
Tablo 2: ÜK ve $\mathrm{CH}$ grubunda kırık sıklığ

\begin{tabular}{lllll} 
& & ÜK(n=18) & $\mathrm{CH}(\mathrm{n}=33)$ & Toplam(n=51) \\
\hline kırık & var & $11(\% 68)$ & $16(\% 48)$ & $27(\% 52)$ \\
& Yok & $7(\% 42)$ & $17(\% 52)$ & $24(\% 48)$ \\
\hline
\end{tabular}

ÜK: Ülseratif Kolit, CH: Crohn Hastalı̆ı

Tablo 3:Her iki grupta kemik mineral yoğunluğu ve kırık ilişkisi

\begin{tabular}{llll}
\hline$"$ & ÜK+kırı̆ı olan & CH+kırı̆ı olan & P \\
\hline L1-L4-normal & $9(\% 81)$ & $9(\% 60)$ & 0.18 \\
$\quad$ osteopenik & $2(\% 19)$ & $3(\% 20)$ & 0.11 \\
$\quad$ osteoporotik & 0 & $3(\% 20)$ & 0.17 \\
Femur boynu- normal & $10(\% 90)$ & $9(\% 60)$ & 0.14 \\
$\quad$ osteopenik & $1(\% 7)$ & $5(\% 33)$ & 0.07 \\
osteoporotik & 0 & $1(\% 10)$ & 0.10 \\
\hline
\end{tabular}

\section{TARTIŞMA}

Ülseratif kolit ve Crohn hastalığı genellike genç erişkin yaşta tanı alan; yüksek morbidite nedeni ile hastaların yaşam kalitesini önemli düzeyde etkileyen kronik seyirli barsak hastalıklarıdır. Hastalığın tanı konma yaşı $\mathrm{CH}$ için $20^{\prime}$ li yaşlar UK için 30'lu yaşlar olmakla beraber herhangi bir yaşta da tanı konulabilir. Hastaların yaklaşık \%10-15'ine erişkin yaştan önce tanı konulmaktadır. Çalışma grubumuzda hastalarımızın çoğunun başlangıç yaşı 30'lu yaşlar idi. Çoğu $\mathrm{CH}$ ile ilgili çalışmalarda hafif bir kadın hakimiyeti varken, genellikle $\% 50$ - 60 arasında, ÜK grubunda hafif bir erkek hakimiyeti vardır (11). Çalışmaya aldığımız Crohn hastalarında kadın hakimiyeti (\%66), ÜK grubunda ise (\%55) düşük düzeyde erkek hakimiyeti mevcut idi.

OP; IBH'ı olan kişilerde sık görülen, genç hastalarda dahi vertebral kompresyon kırıklarına yol açabilen önemli bir sağlık sorunudur. IBH'nda görülen kemik hastalığı ile ilişkili genel bilgilere göre, gerek ÜK gerek $\mathrm{CH}$ olan hastalarda normal nüfusla kıyaslandığında KMY'nda azalma olduğu bilinmektedir. İBH'nda osteoporoz riski \% 15 civarındadır, bu risk yaşıllarda ve vucüt kitle indeksi düşük olanlarda daha fazladır. Kırık riski yıllık \% 1 olup yaş ilerledikçe artmaktadır. İBH'ndaki KMY azalmasında yaş önemli bir risk faktörü olmakla birlikte, hastalığın tipi (ÜK veya $\mathrm{CH}$ ) osteoporoz ile ilişkili değildir. İBH ile ilişkili osteoporozda inflamatuar sitokinlerin salınımı, persistan hastalık aktivitesi, malabsorbsiyon, malnütrisyon,kortikosteroid kullanımı, fiziksel aktivite azlığı,sigara kullanımı,seks hormonlarının düzeyi, vitamin D eksikliği gibi birçok neden suçlanmaktadır; düşük mineral yoğunluğunun patogenezinin multifaktöriyel olduğu ileri sürülmektedir.

$\mathrm{CH}$ ile ilgili ortalama yaşın 40 olduğu bir çalışmada osteoporoz \% 15 olarak saptanmıştr. Osteopeni prevalansı ise \% $50 \mathrm{dir}(8)$. ÜK hastalarında osteoporoz riski Crohn hastalı̆ı̆ından daha düşüktür. Birçok çalışmada KMY ve VKI de normal bulunmuştur. Hela ve arkadaşlarının yapthğı bir çalışmada 56 Crohn hastası incelenmiş; Femur ve vertebra KMY DEXA ile ölçülmüştür. Osteoporoz \% 35,7 ve osteopeni \% 23,2 sıklığında bulunmuştur.VKi, kolonik tutulum ve glukokortikoid tedavi ile OP gelişimi arasında ilişki saptanmışttr. Düşük VKi'nin düşük KMY için bağımsız bir risk faktörü olduğu belirtilmiştir(10). Çalışma grubumuzda lomber bölge kemik yoğunluğu(t skoru) ÜK grubunda \%24 osteopenik,\%10 osteoporotik düzeyde iken; $\mathrm{CH}$ grubunda $\% 36$ osteopenik,\%13 osteoporotik olarak saptandı. 
Barsak rezeksiyonu yapılan hastalardaki kortikal kemik kaybı, rezeksiyon geçirmemiş olanlara göre daha fazladır. Bu durum, Crohn hastalığındaki osteoporozdan malabsorbsiyondan çok inflamasyonla ilişkili faktörlerin sorumlu olabileceğini düşündürmektedir.(8) Pigot ve arkadaşlarının yaptığı 70 yaşına kadar olan IBH olan hastaların dahil edildiği bir çalışmada, 61 iBH hastasının \% 23 ünde vertebra ve femur boynunda daha önce belirlenmiş yaşa ve cinsiyete bağlı normal değerlerin 2 SD’ndan daha fazla kemik mineral yoğunluğu azalması olduğu bulunmuştur. 34 ülseratif kolit hastasının 13 ünden (\% 38,2) ilioanal anastamoz anamnezi alınmıştır. Hasta grubumuzda ÜK olgularının hiçbirinde barsak rezeksiyonu anamnezi yok iken,Crohn hastalarının \%33'ü opere edilmişti. Yine sadece $\mathrm{CH}$ grubunda apendektomi anamnezi mevcut idi. Bu da Crohn hastalığının tutulum yeri ve hastalığın ÜK'e göre daha şiddetli seyrettiği hakkında fikir vermektedir.

Silvennoinen ve arkadaşları sigara içiminin ve diğer yaşam şartlarının IBH hastalarında KMY ölçümleri üzerine etkisini araştırmışlardır. Çalışmanın sonucunda sigara kullanımının kadın İBH hastalarda düşük KMY ile beraber olduğunu ve bu ilişkinin VKi, ilaç tedavisi ve hastalık tipi ile herhangi bir ilişkisi olmadığını belirtmişlerdir(9). Hasta grubumuzda sigara içen kadınların \%40'ında komber bölgede,\%50'sinde femur boynunda; erkeklerin ise \%50sinde lomber bölgede,\%25'inde femur boynunda osteopeni saptandı.

Jahnsen ve arkadaşlarının yaptığı bir çalışmada 60 Crohn hastası, 60 ülseratif kolit, 60 sağlıklı erişkin incelenmiştir.Femur ve vertebra yoğunlukları DEXA yöntemi ile ölçülmüştür. Kortikosteroid kullanımı, VKI ve cinsiyet Crohn hastalığında KMY için önemli bir önceden belirleyici olarak bulunmuştur. ÜK için VKi ve cinsiyet önemli bulunmuştur. $\mathrm{CH}^{\prime}$ nda hastalığın yeri ve barsak rezeksiyonu KMY üzerinde etkili bulunmamıştır(10). Çalışma grubumuzda aynı şekilde her iki grupta da hastalık tutulum yeri ile KMY arası ilişki bulunamadı.

IBH'nda hem diyetle alım yetersizliği hem de emilim bozukluğuna bağlı olarak özellikle Crohn hastalarında D vitamini eksikliği görülmektedir. D vitamini eksikliği de osteoporoz gelişimini hızlandıran nedenlerden biridir. Fakat çalışmamızda kalsiyum/D vitamini kullanımı ile KMY arasında ilişki gözlenmedi.

IBH 'nda kırık riskini ve sıklığı konusunda bilgilerimiz sınırlıdır. Yapılan çalışmalardan elde edilen verilere göre IBH'nda \%5-27 oranında kırık görülmektedir. Yakın zamanda Bernstein ve arkadaşlarının yaptı̆̆ bir çalışmada ;kontrol grubu ile kıyaslandığında İBH olanlarda \%41 oranında kırık riski belirlenmiştir. ÜK ve $\mathrm{CH}$ grubunda kırık riski yönünden benzer sonuçlar elde edilmiştir. Fakat Vestergaard ve arkadaşlarının yaptığı bir çalışmada 383 Crohn hastası, 434 Ülseratif kolit hastası ve 635 kontrol deneği alınmış;kırık için risk faktörleri ve kırık oranlar araştırılmıştır. Fraktür riskinin Crohn hastalığı olan kadın hastalarda arttiğı $(R R=2,5)$ fakat erkek hastalarda $(R R=0,6)$ veya ülseratif koliti olan hastalarda $(R R=1,1)$ artmadığı tespit edilmiş; kırıkların vertebra, ayak, ayak parmağı, kaburga kemiği ve pelvis kemiklerinde olduğu görülmüştür. Fraktür riskinin Crohn hastalığında sistemik kortikosteroid kullanımı süresinin artşı ile parale olduğu fakat ülseratif kolitte kırık riskinin artmadığ tespit edilmiştir(12). Çalışmamızda Genant yöntemi kullanılarak 2 yönlü torakolomber vertebra grafilerine bakılarak hastalar kırık açısından tarandığında bütün hastalarda kırık yüzdesi \%52 olarak hesaplandı. ÜK grubu hastaların \%68'inde, $\mathrm{CH}$ grubu hastaların ise \%48'inde kırık mevcut idi. Fakat yaş ve cinsiyet açısından her iki grupta da vertebra kırığı oluşumu yönünden ilişki bulunamadı. Türkiye'de vertebral OP prevalans erkeklerde \% 54, kadınlarda \% 46 olarak tespit edilmiş, kadınlarda kama tipi, erkeklerde ise bikonkav kırıklara daha sık rastlanmıştır (6). Yapılan çalışmalarda osteoporoza bağlı vertebra kırıklarının daha çok kama tipi kırık şeklinde olduğu belirlenmiştir. Çalışma grubumuzda da hem kadınlarda (\%64) hem de erkeklerde (\%50) daha yüksek oranda kama tipi kırık mevcut idi. Hastaların \%31 inde kama (wedge) tipi, \%9.8 inde plaka(endplate) tipi, \%11,8 inde ise ezilme (crush)tipi kırık mevcut idi. 
ÖZDEMIR ve ark.

Inflamatuar Barsak Hastalığında Osteoporoz Vertebra Kırıkları
Bozok Tip Derg 2014,4(1):48-54

Bozok Med J 2014;4(1):48-54
Kırıkların lokalizasyonu değerlendirildiğinde ise \%2sinin üst torakal bölge (T1-T2-T3-T4), \%31,4 ünün orta torakal bölge (T5-T6-T7-T8), \%17,6 sının da alt torakal bölgede (T9-T10-T11-T12) olduğu belirlendi. Her iki hastalık grubunda kırığı tespit edilenlerin \%9.8 inde 1.derece, \%39,2 sinde 2.derece, \%3.9 unda 3.derece kırık bulundu.

Sonuç olarak IBH'nda osteoporoz patogenezi multifaktöriyeldir. Kendi çalışmamızı da göz önünde bulundurduğumuzda IBH'nda OP gelişimi ileri yaş,düşük VKI,sigara kullanımı, hastalık seyrinde barsak rezeksiyonu geçirmiş olmakla pozitif korelasyon gösterirken; hastalık tutulum yeri ve D vitamini eksikliği arasında negatif korelasyon görülmektedir. OP da hastalarda ağrı genellikle olmadığı ve OP’un ileri dönemlerinde ancak vertebra kırığı oluşumunda ağrı hissedilmeye başladığı için erken tanı pek mümkün olamamaktadır. Vertebra deformitelerine \%40-50 oranında rastlanabilmektedir. Çalışmamızda da vertebra kırığı sıklığı \%52 olarak bulundu ve kırık gelişimi açısından yaş,cinsiyet arasında farklılık saptanmadı. Diğer önemli bir bulgu da; kırık gelişiminde KMY nun düşünüldüğü kadar önemli düzeyde etkisinin olmaması idi. Çalışmamızda hasta sayısının az olması dezavantaj olmuştur. İlaç anamnezi ne kadar ayrıntılı sorulmuş olsa da eski dönemlere yönelik ilaç kullanımı tam anlamıyla değerlendirilememiştir. Daha ayrıntılı bir çalışma yapabilmek için hastalara manyetik rezonans inceleme düşünülmüş olsa da maliyet nedeni ile yapılamamıştır.

\section{KAYNAKLAR}

1. Dinca M, Fries W, Luisetto G. Evolution of osteopenia in inflammatory bowel disease. Am J Gastroenterol. 1999;94(9):1292-7.

2. Bjarnason I, Macpherson A, Mackintosh C. Reduced bone density in patients with inflammatory bowel disease. Gut. 1997;40(4):228-33.

3. Compston J. Osteoporosis in inflammatory bowel disease. Gut. 2003;52(1):63-4.

4. Vestergaard P, Krogh K, Rejnmark L. Fracture risk is increased in Crohn's disease, but not in ulcerative colitis. Gut. 2000;46(2):176-81.
5. Abitbol V, Roux C, Chaussade S. Metabolic bone assessment in patients with inflammatory bowel disease. Gastroenterolgy. 1995;108(6):417-22.

6. Conference Report.Consensus Development Conference Diagnosis, Prophylaxis and Treatment of Osteoporosis. The Ame of Medicine. 1993;94(7):646-50.

7. Schapira D, Schapira C. Osteoporosis et al: The Evaluation of A Scientific Term. Osteoporosis Int. 1992; 2(2):164-7.

8. Süleymanlar í. İnflamatuvar barsak hastalıklarında ekstraintestinal tutulum. İnflamatuvar Barsak Hastalıkları. 2006;1(1):194-5

9. Jahnsen J, Falch JA, Aadland E, Mowinckel P. Bone mineral density is reduced in patients with crohn"s disaese but not in patients with ulcerative colitis: a population based study. Gut. 1997; 40(1):313-319.

10. Heijckmann AC,Hujiberts MSP,Schoon EJ, Geusens $P$, de Vries J, Menheere PP, et al. High prevelance of morphometric vertebral deformities in patients with iBD, Eur J Gastroenterol hepatol. 2008;20(8):740-7.

11. Leftus EV, Sandborn VJ. Epidemiolgy of inflammatory bowel disease. Gasroenterol Clin N Am. 2002;31(1):1-20. 12. Hela $S$, Nihel $M$, Faten $L$, Monia F, Jalel B, Azza F, et al. Osteoporosis and Crohn disease. Joint Bone Spine. 2005; 72(5):403-7. 